\title{
Design and development of a servo-controlled target- oriented robotic micro-dose spraying system in precision weed control
}

\author{
Projeto e desenvolvimento de um sistema de \\ pulverização de microdoses robótico orientado ao alvo \\ controlado por servo no controle de precisão de ervas \\ daninhas
}

\author{
Ömer Barış Özlüoymak*
}

Highlights

A prototype mobile robot was constructed and controlled by using LabVIEW software.

The system was tested as a micro-dose spraying system on artificial weed samples.

The artificial weed samples were treated according to their coordinates.

Tracking and targeting performances of the spraying system were determined visually.

Consumption, deposition and coverage rate experiments were conducted.

\begin{abstract}
The broadcast spraying method using excessive amounts of pesticides is generally preferred for weed control in agriculture. In this study, a mobile robot was developed and tested on artificial weed targets for a micro-dose spraying system to reduce amount of liquid sprayed for weed control. A prototype mobile robot consisting of a robotic platform, machine vision and steerable spraying unit was constructed and controlled by using LabVIEW software and tested to evaluate the applicability of the spraying system. The greenness method and segmentation algorithm were used to extract artificial weeds from the background. The artificial weed samples were treated according to their coordinates by using a servo-based microdose spraying needle nozzle. The experiments were carried out at speeds of $0.42,0.54,0.66,0.78$ and 0.90 $\mathrm{km} \mathrm{h}^{-1}$ to evaluate the performance of the spraying system under laboratory conditions. The tracking and targeting performances of the mobile spraying system were observed visually. Consumption, deposition and coverage rate experiments were carried out by using graduated cups, filter papers and water-sensitive papers to evaluate the spraying efficiency of the system under $200 \mathrm{kPa}$ of spraying pressure. The results showed that the targeted micro-dose spraying method saved approximately $95 \%$ of the application volume compared with the broadcast spraying method. Higher spraying efficiency was determined at the middle locations rather than at the edge locations according to the amount of deposition and coverage rate results.

1 Assist. Prof. Dr., Çukurova University, Faculty of Agriculture, Department of Agricultural Machinery and Technologies Engineering, Adana, Turkey. E-mail: ozluoymak@cu.edu.tr

* Author for correspondence
\end{abstract}

Received: Aug. 08, 2020 - Approved: Dec. 31, 2020 
The servo-controlled target-oriented weed control system that was developed was tested experimentally and found to be very efficient.

Key words: LabVIEW. Machine vision. Precision weed control. Spraying needle nozzle.

\section{Resumo}

O método de pulverização por difusão usando quantidades excessivas de pesticidas é geralmente preferido para o controle de ervas daninhas na agricultura. Neste estudo, um robô móvel foi desenvolvido e testado em alvos artificiais de ervas daninhas para um sistema de pulverização de microdoses para reduzir a quantidade de líquido pulverizado para o controle de ervas daninhas. Um protótipo de robô móvel consistindo de uma plataforma robótica, visão de máquina e unidade de pulverização dirigível foi construído e controlado usando o software LabVIEW e testado para avaliar a aplicabilidade do sistema de pulverização. O método de verdura e o algoritmo de segmentação foram usados para extrair ervas daninhas artificiais do fundo. As amostras de ervas daninhas artificiais foram tratadas de acordo com suas coordenadas usando um bico de agulha de pulverização de micro-dose baseado em servo. Os experimentos foram conduzidos nas velocidades de 0,42; 0,54, 0,66, 0,78 e 0,90 $\mathrm{km} \mathrm{h}^{-1}$ para avaliar o desempenho do sistema de pulverização em condições de laboratório. Os desempenhos de rastreamento e direcionamento do sistema de pulverização móvel foram observados visualmente. Experimentos de consumo, deposição e taxa de cobertura foram realizados usando copos graduados, papéis de filtro e papéis hidrossensíveis para avaliar a eficiência de pulverização do sistema sob pressão de pulverização de $200 \mathrm{kPa}$. Os resultados mostraram que o método de pulverização de microdoses direcionado economizou aproximadamente 95\% do volume de aplicação em comparação com o método de pulverização por difusão. A maior eficiência de pulverização foi determinada nos locais do meio, em vez de nos locais das bordas, de acordo com a quantidade de deposição e os resultados da taxa de cobertura. O sistema de controle de ervas daninhas orientado ao alvo servo-controlado que foi desenvolvido foi testado experimentalmente e considerado muito eficiente.

Palavras-chave: Bico de agulha de pulverização. Controle preciso de ervas daninhas. LabVIEW. Visão de máquina.

\section{Introduction}

Weeds negatively affect agricultural crop production by competing with crop plants for resources, including soil moisture, nutrients, and light. The traditional broadcast spraying method, which is applied continuously onto farmland irrespective of whether there are targets when the sprayer passes through, results in up to $60-70 \%$ off-target losses. While broadcast spraying is applied across the field as a whole, targeted spraying systems can specifically target damaged or infected plots or plants in the field through detection and allow timely control of the sprayer operation, which results in reduced waste and environmental pollution (Song, Sun, Li, \& Zhang, 2015).

In recent decades, herbicide usage has been reduced significantly through sitespecific control of weeds, and satisfactory production levels are met by using patch spraying without compromising efficacy or damaging the environment (Gonzalez-deSoto, Emmi, Perez-Ruiz, Aguera, \& Gonzalez- 
de-Santos, 2016; Jafari, Mohtasebi, Jahromi, \& Omid, 2006b; Loghavi \& Mackvandi, 2008; Loni, Loghavi, \& Jafari, 2014; Shirzadifar, Loghavi, \& Raoufat, 2013; Tellaeche, BurgosArtizzu, Pajares, \& Ribeiro, 2008; Timmermann, Gerhards, \& Kühbauch, 2003; Yang, Prasher, Landry, \& Kok, 2002; Yang, Prasher, Landry, \& Ramaswamy, 2003). Many researchers have developed machine vision-based real-time site-specific herbicide application systems by using image-processing techniques to eradicate weeds and tested and evaluated them under laboratory and field conditions. Within this framework, previous studies have provided herbicide savings ranging between $52 \%$ and $79.4 \%$ (Jafari, Jahromi, Mohtasebi, \& Omid, 2006a; Loghavi \& Mackvandi, 2008; Sabanci \& Aydin, 2017; Shirzadifar et al., 2013; Tangwongkit, Salokhe, \& Jayasuriya, 2006; Tellaeche et al., 2008; Tian, 2002; Timmermann et al., 2003; Wan Ishak \& Rahman, 2010; Yang et al., 2002, 2003).

There is an increasing need to reduce spray liquid usage because of health and environmental concerns. Today, eco-friendlier and more economical systems have been developed by applying ultralow doses of herbicides directly to the target weeds because of the development of agricultural robots and automation. Midtiby, Mathiassen, Andersson and Jørgensen (2011) developed an intelligent real-time micro-spraying weed control system. Since the area between two nozzles was quite large, the system was able to effectively control weeds larger than $11 \mathrm{~mm}$ $\times 11 \mathrm{~mm}$. Young and Giles (2013) developed a common supply manifold-based design to provide pressurized liquid to an array of high-speed solenoid valves. The liquid jets, namely, sprays, were tested theoretically and experimentally and found to be very efficient.
Zhang, Staab, Slaughter, Giles and Downey (2012) developed and tested a hyperspectral imaging system to selectively deliver foodgrade oil heated to approximately $160{ }^{\circ} \mathrm{C}$ for intra-row weed control in early growth tomatoes. High-temperature organic oil was applied to the weeds using a pressurized micro-dosing pulsed jet. Nieuwenhuizen, Hofstee and van Henten (2010) developed and evaluated the performance of a machine vision-based detection and control system combined with a micro-sprayer with five needles for volunteer potatoes in sugar beet fields. Zhao, Zhao, Wang and Zhang (2016) proposed a target spray robot with a composite vision servo-system to spray onto the canopy of interval planting crops. Underwood et al. (2015) presented a microdot-targeted system for weed control by using a steerable spraying robot to reduce the input costs and detrimental environmental impact. Lee, Slaughter and Giles (1999) developed a real-time intelligent robotic system by using machine vision consisting of an array of eight nozzles for precision weed control in tomato seed lines. Lamm, Slaughter and Giles (2002) developed and tested a robotic weed control system for cotton plants. Berenstein and Edan (2017) presented a human-robot collaborative sprayer designed for site-specific targeted spraying. The robotic system showed a $50 \%$ reduction in the sprayed material. The authors concluded that tilting or pivoting the system during field applications might have prevented the accurate targeting of spray deposition onto some weeds.

The objective of this study was to develop a servo-based target-oriented robotic interrow real-time weed control system using machine vision to spray only the canopy of artificial weeds. A mobile prototype spraying 
system containing one steerable spraying needle nozzle controlled by a solenoid valve was designed, constructed and evaluated by using LabVIEW software under controlled laboratory conditions. The novel spraying system with a steerable needle nozzle was designed and developed to reduce the amount of liquid sprayed for weed control, overcome problems in precision spraying systems, follow the recommendations and fill the deficiencies reported in the literature, such as: i. some weeds less a certain size cannot be detected and sprayed, ii. weeds remaining between two needle nozzles (array of needles) are not be sprayed, iii. mobile systems first must stop, and the spraying process is carried out according to generated weed maps (static method/stationary systems), and iv. tilting or pivoting of the spraying systems during spraying applications is recommended for accurate targeting. The amount of deposits on artificial weeds depending on mobile robot speed was also examined and determined by using a spectrofluorophotometer in addition to the volumetric consumption and coverage rate determination.

\section{Materials and Methods}

\section{Materials}

\section{Mobile robot and spraying system}

The test of the prototype mobile robot consisting of a robotic platform, machine vision, control, and steerable spraying units was conducted in the spraying laboratory at the Department of Agricultural Machinery and Technologies Engineering of Çukurova University, Adana, Turkey. A schematic view of the servo-based target-oriented robotic weed control system is shown in Figure 1.

A 0.37-kW electric motor (WAT, QS71M4B) coupled to a gear reducer (Yılmaz Redüktör, $A 12-71 M N B)$ was used to move the system on the rails. The speed of the mobile system was adjustable by using a variable frequency controller (ABB micro drives, ACS355). Having the ability to move back and forth automatically, the mobile system was equipped with two diffuse mode sensors (Pepperl+Fuchs, GLV18-8-450/115/120) placed on both ends of the robotic platform to detect the border apparatus. An inductive proximity sensor (Sick, IME08-04NPSZW2S) was also installed to measure the speed of the mobile robot.

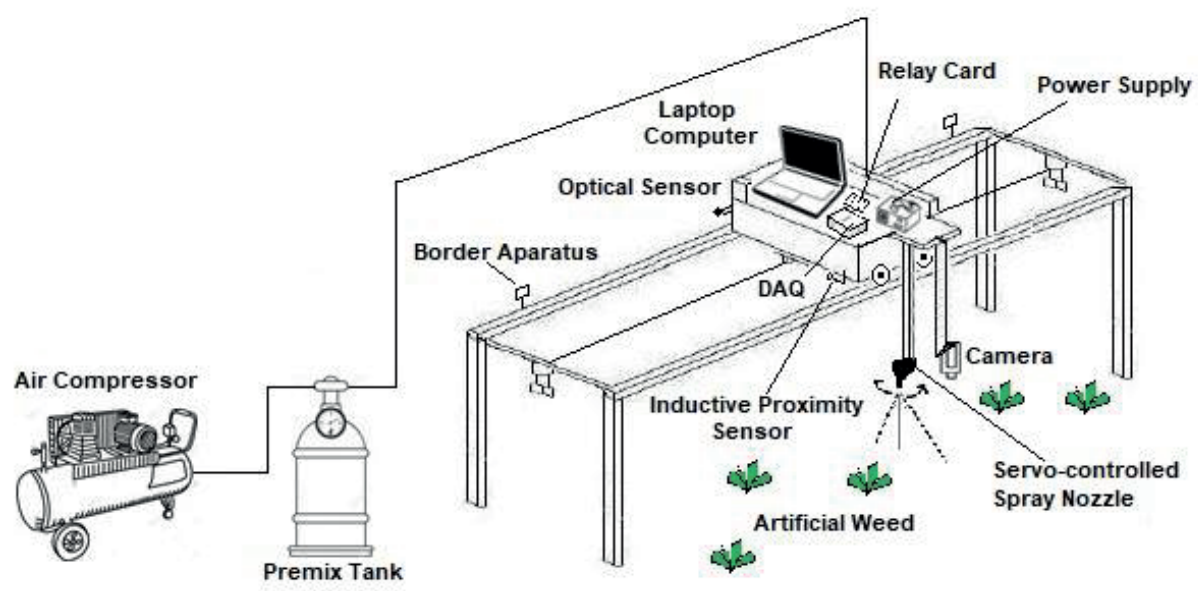

Figure 1. Schematic view of a servo-based target-oriented robotic weed control system. 
A camera (Logitech C270) was used for artificial weed detection and tracking with a preset height (650 $\mathrm{mm}$ above the ground) in the machine vision unit. The camera, which had a $4 \mathrm{~mm}$ focal length and a resolution of $1280 \times 960$ pixels, was equipped with a CMOS sensor. A laptop computer (Acer, Aspire E15), a data acquisition device (NI USB-6009, National Instruments Corporation, AustinTexas-USA), and a $12 \mathrm{~V} 16$ channel relay card comprised the control unit of the real-time robotic spraying system. The control and automation of the system, image acquisition, processing, and artificial weed-tracking procedures were carried out with LabVIEW (National Instruments Corporation, Austin, Texas, USA) software. Two DC power supplies (Pacific, 2305D+) were also used on the mobile system.

A steerable spraying unit, which consisted of a lubricator (STNC, TC 2010-02), an air compressor (Sarmak, Çita), a premix tank, a 12 V DC normally closed solenoid valve (Tork, S101003145N), an RC servomotor (PowerHD, $1212 \mathrm{TH}$ ) with an operating speed of $0.10 \mathrm{~s}, 60^{\circ}$ controlled spraying needle nozzle (with $25 \mathrm{~mm}$ needle length) and other necessary hardware was designed and fabricated for the system. A portable reconfigurable I/O device (NI myRIO 1900, National Instruments Corporation, Austin-Texas-USA) was used to change the sprayer angle according to the $y$-coordinate of the artificial weed sample. The artificial weed targets were attached and fixed to the ground by using double-sided tape to keep them immobilized.
A spray nozzle (Lechler standard flat fan nozzle, $110-02$ ) with a $110^{\circ}$ spraying angle and 0.2 -gal $\mathrm{min}^{-1}$ flow rate at $275.79 \mathrm{kPa}(40$ PSI) nominal pressure was used for broadcast spraying experiments. Brillant Sulpho Flavin (BSF) as a tracer material, filter papers (Whatman, Schleicher \& Schuell, Ø 42.5 mm), a spectrofluorophotometer (Shimadzu, RF6000) and a shaking device (Nüve, SL 350) were also used to determine the amounts deposited by the target-oriented spraying system. In addition, water-sensitive papers (Syngenta, 26×76 mm) were used to determine the coverage rate of the spraying needle nozzle, and image-processing software was developed with Vision Acquisition Software (National Instruments Corporation, AustinTexas-USA) for the papers to be analysed. The water-sensitive papers were scanned by a scanner (Epson, WF-2520) at 300 dpi resolution.

\section{Methods}

Real-time object detection, steering of the spraying needle nozzle, and targetoriented spray application were performed for the artificial weeds under controlled laboratory conditions while the mobile system was in motion. The system architecture of the mobile robot is illustrated in Figure 2. 


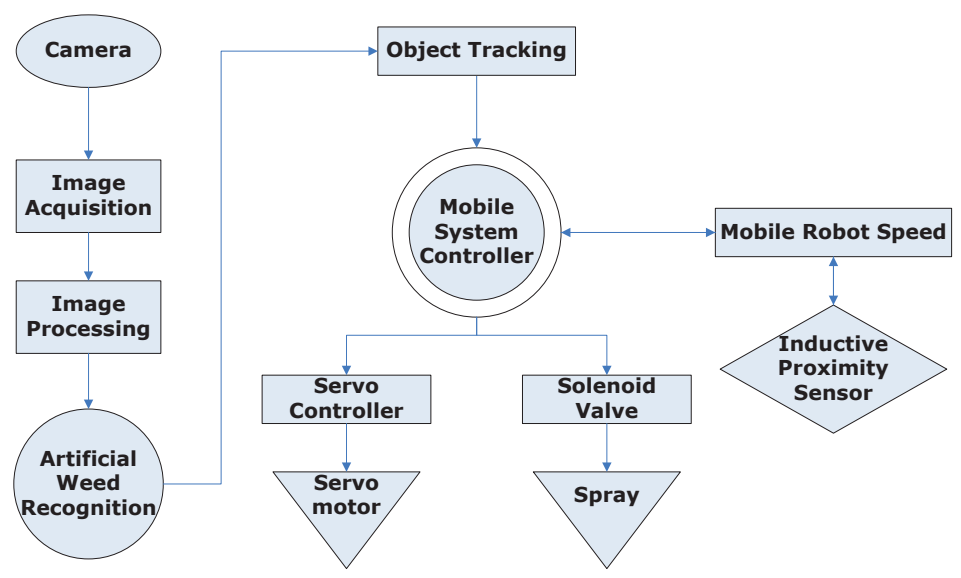

Figure 2. The system architecture of the mobile robot.

Xiong, Ge, Liang and Blackmore (2017) argued for two different weeding methods, namely, static and dynamic weeding. While the robot performs weeding as it continues moving in the dynamic weeding process, in the static weeding process, the platform stops, carries out the laser operation, and then moves on. In this study, the dynamic weeding method was used in a servo-based target-oriented robotic weed control system.

Image-processing and object tracking methods

The captured RGB image was separated into red $(R)$, green $(G)$ and blue $(B)$ components to apply the greenness method, denoted as

$$
E x G=2 \times G-R-B
$$

where $E x G$ is the excess green vegetation index and $R, G$, and $B$ are the colour components of the image. This index provided a near-binary intensity image outlining a plant region of interest. Next, a binarization technique was applied using a selected threshold value for each set of images. The optimum threshold value was set to 40 in line with the results of the preliminary studies, where the intensity values ranged from 0 to 255 . The same threshold value was used by Yang et al. (2002, 2003) as well in their studies. Many researchers have widely cited and employed the same technique in their recent studies (Jafari et al., 2006a; Loni et al., 2014; Sabanci \& Aydin, 2017; Shirzadifar et al., 2013; Yang et al., 2002, 2003). Plant regions from the background can be accurately segmented by using binary images (Meyer \& Camargo, 2008). The objects can be extracted from the background by selecting a threshold value $(T)$ to obtain the binary image. The segmented image is denoted by

$$
g(x, y)=\left\{\begin{array}{l}
1 \text { if } f(x, y)>T \\
0 \text { if } f(x, y) \leq T
\end{array}\right.
$$

where $g(x, y)$ is the processed image; $f(x, y)$ is the pixel value of the image on the $x^{\text {th }}$ column and $\mathrm{y}^{\text {th }}$ row; and $T$ is the selected thresholding value (Gonzalez, Woods, \& Masters, 2008).

The average values of pixel coordinates of the artificial weeds were then calculated and accepted as the centroid coordinates of the target. The pixel coordinates of the artificial 
weed centroids were transformed into realworld coordinates. The centroid position $(x$ - and $y$-coordinates) of each artificial weed was used for the object tracking and targetoriented spraying processes.
As shown in Figure 3, the spraying procedure of the system was based on the image acquisition and processing system. The locations of the artificial weed centroids were also obtained by using image-processing techniques.

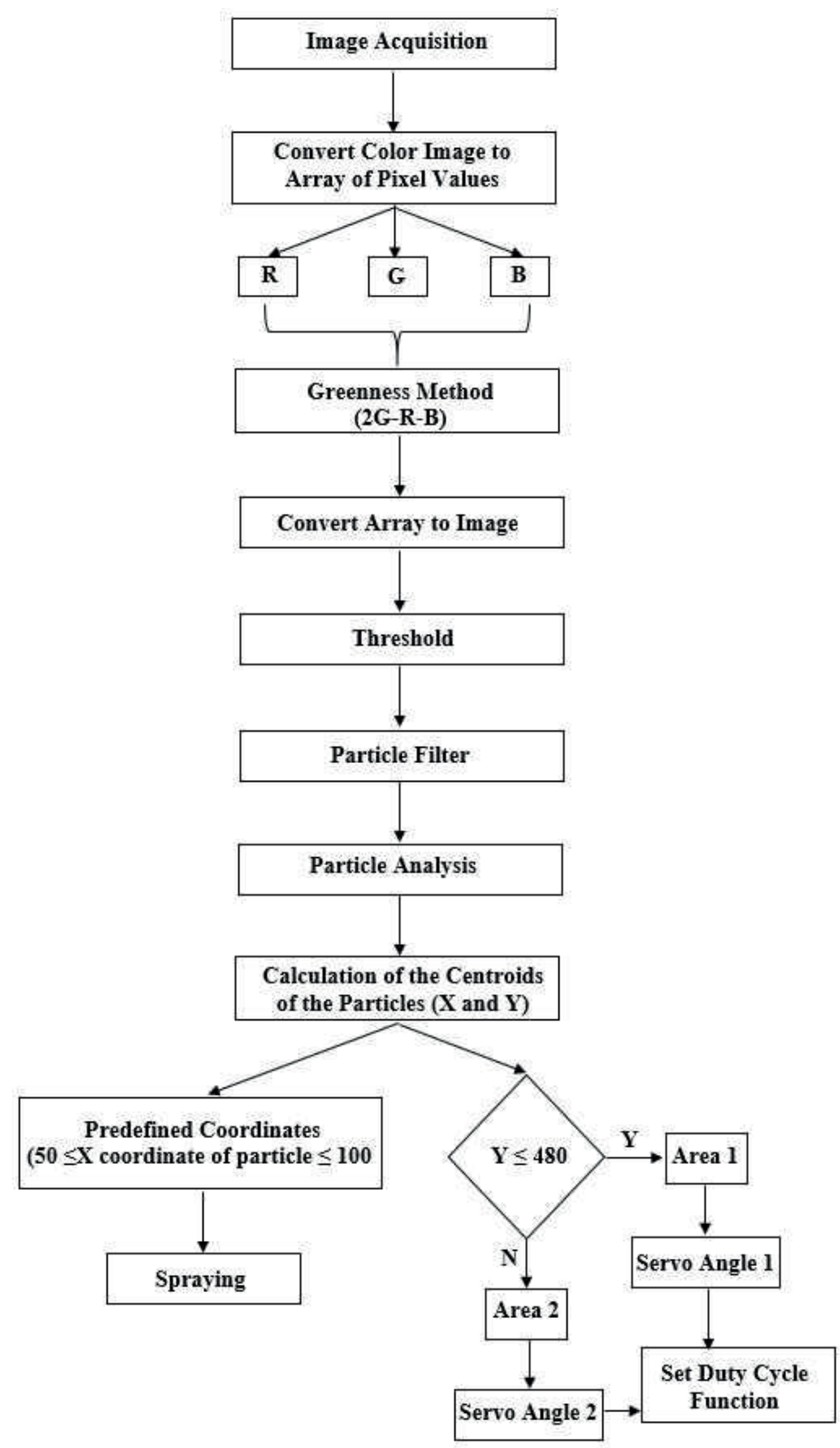

Figure 3. Image-processing and spraying procedure steps of the spraying system. 


\section{Targeting algorithm}

Blasco, Aleixos, Roger, Rabatel and Moltó (2002) and Underwood et al. (2015) designed parallel robotic arms with 6 DOFs (degrees of freedom) for selective precision spraying and mechanical weeding. However, these systems are very expensive and complex. Xiong et al. (2017) designed arms with 2 DOFs by adopting two gimbals in the laser weeding robot that can work in parallel. In the Blasco et al. (2002) study, the platform stopped, carried out the laser operation by using two servo actuators and then moved on (for static weeding). As argued by the authors in the literature, the speed of static weeding is not as fast as that of dynamic weeding. In an effort to address the issues raised by the authors, in this study, a mobile platform was designed and developed to increase the weed-spraying speed and targeting accuracy.

Two algorithms were used in the developed mobile system. Image-processing and targeting algorithms ran simultaneously and were connected to each other. The steering angle of the servo motor-coupled needle nozzle was calculated by the targeting algorithm according to the centroid position of the artificial weed obtained from the imageprocessing algorithm.

While the mobile system was moving on the rail, the artificial weeds placed in random locations along a row were tracked, and their centroid positions ( $\mathrm{x}$ - and $\mathrm{y}$-coordinates) were transferred to the computer instantaneously. The spraying needle nozzle was mounted on the servomotor connected to the base of the mobile system (Figure 4).

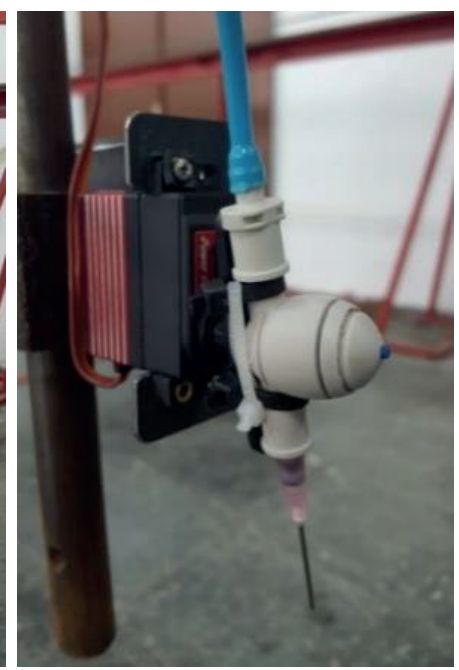

Figure 4. Servomotor coupled needle nozzle.

As shown in Figure 5, the servomotor angle position was controlled according to the $y$-coordinate of the artificial weed depending on its positioning in either Zone 1 or Zone 2.
The spraying process was only performed according to the $\mathrm{x}$-coordinate information of the artificial weed because the working direction of the mobile system was in a single 
plane. The spraying procedure was performed by activating the servomotor-controlled microsprayer in the $y$-axis while the artificial weed target was passing according to the predefined coordinates.

The software that was developed converted the pixel position of the artificial weed to the angle value for steering the servomotor by using the trigonometric calculations explained below. The centroids of artificial weeds were converted into servo position angles based on the following trigonometric equations:

$$
\begin{aligned}
& \tan \alpha=\frac{a}{h} \\
& \tan \beta=\frac{b}{h}
\end{aligned}
$$

$$
\begin{array}{r}
h=\frac{a}{\tan \alpha}=\frac{b}{\tan \beta} \\
a \times \tan \beta=b \times \tan \alpha \\
\tan \beta=\left(\frac{b \times \tan \alpha}{a}\right) \\
\beta=\tan ^{-1}\left(\frac{b \times \tan \alpha}{a}\right)
\end{array}
$$

where $h$ is the height of the camera from the ground. The width of the image is known (960 pixels $=436.8 \mathrm{~mm}$ ), and the angle $\alpha$ is one-half of the horizontal field of view (FOV). $\beta$ is the calculated steering angle of the needle nozzle. The value of $b$ can change according to the presence of artificial weeds in either Zone 1 or Zone 2.

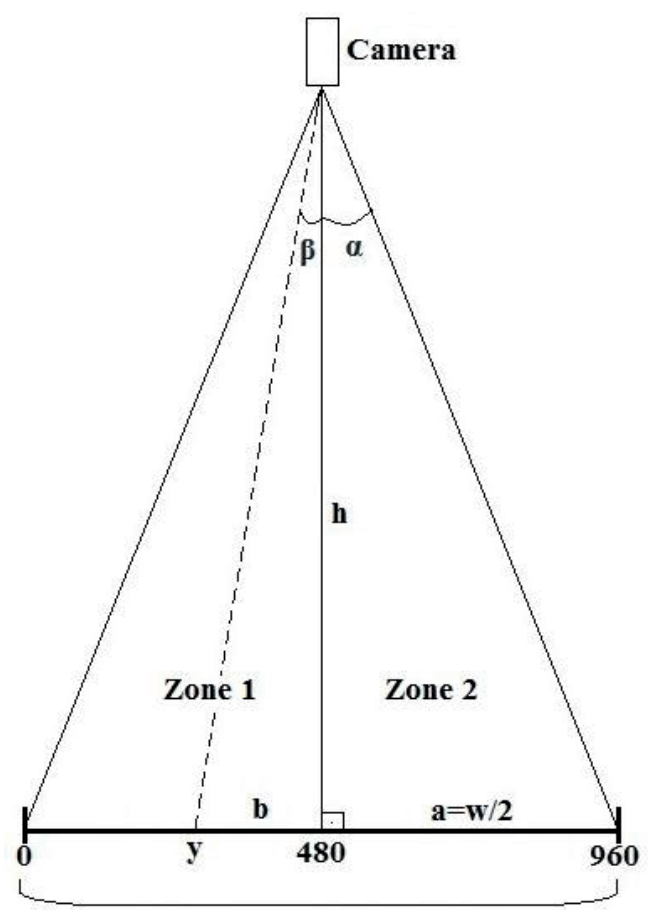

Image Width (w) - pixels

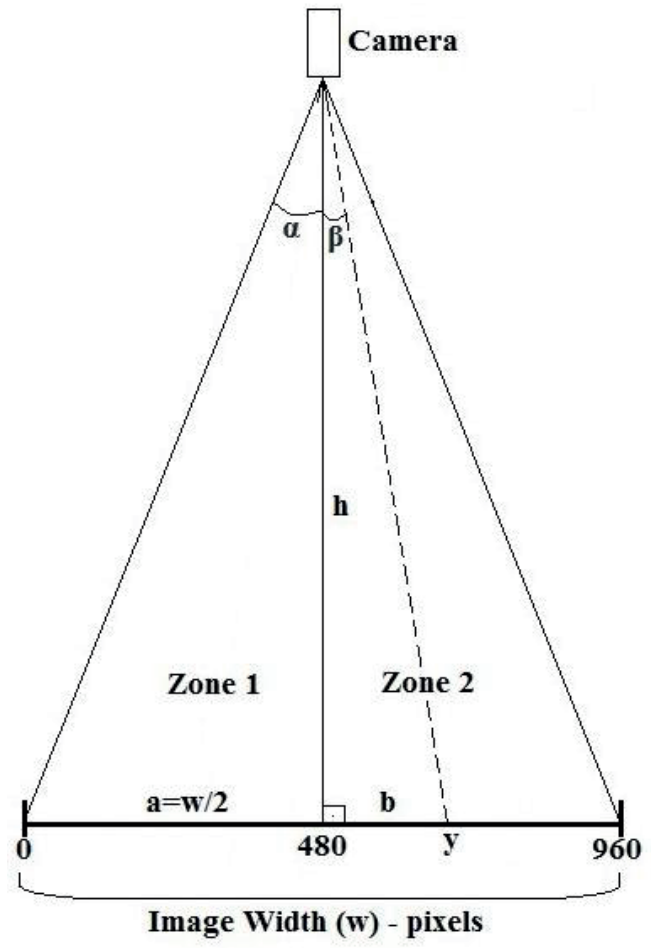

Figure 5. Field of view for the camera according to the $y$-axis Weed in Zone $1 \rightarrow b=(480-y)$ Weed in Zone $2 \rightarrow b=(y-480)$ 


\section{Spray volume consumption tests}

Spray volume consumption tests of the integrated machine vision and solenoidactivated micro-sprayer system were conducted as an indoor application under ideal operating conditions. The travel speeds of the mobile robot were determined to be $0.42,0.54,0.66,0.78$ and $0.90 \mathrm{~km} \mathrm{~h}^{-1}$ in the experiments. The height of the artificial weeds to the spraying unit was $650 \mathrm{~mm}$, and five sequential targets were placed in random locations. The spraying pressure was 200 $\mathrm{kPa}$ for both the micro-sprayer and broadcast spraying experiments. The solenoid valve was pulsed with a $50 \mathrm{~ms}$ spraying duration for each spraying process with $200 \mathrm{kPa}$ spraying pressure in the micro-sprayer experiments. Three replicate trials were carried out, and the spray outputs were compared with those of the broadcast spraying method for each speed to evaluate the volumetric consumption of the micro-sprayer system.
The spraying width of the standard flat fan nozzle used in the broadcast spraying experiments was measured as $1 \mathrm{~m}$ by using a pattern check apparatus, and the optimum working length of the system was determined to be $4 \mathrm{~m}$. The effective spraying area of the mobile robot was calculated as $4 \mathrm{~m}^{2}$ for the broadcast spraying process.

\section{Deposition measurements}

The indoor tests were conducted on a smooth floor using artificial weed samples and filter papers to determine the deposits of the needle nozzle spray pattern. Each filter paper was placed at the centre of the artificial weed since the spraying system was programmed to hit the target according to its centroid coordinates. The layout of the artificial weeds placed along a row in random locations with $750 \mathrm{~mm}$ spacing is shown in Figure 6.
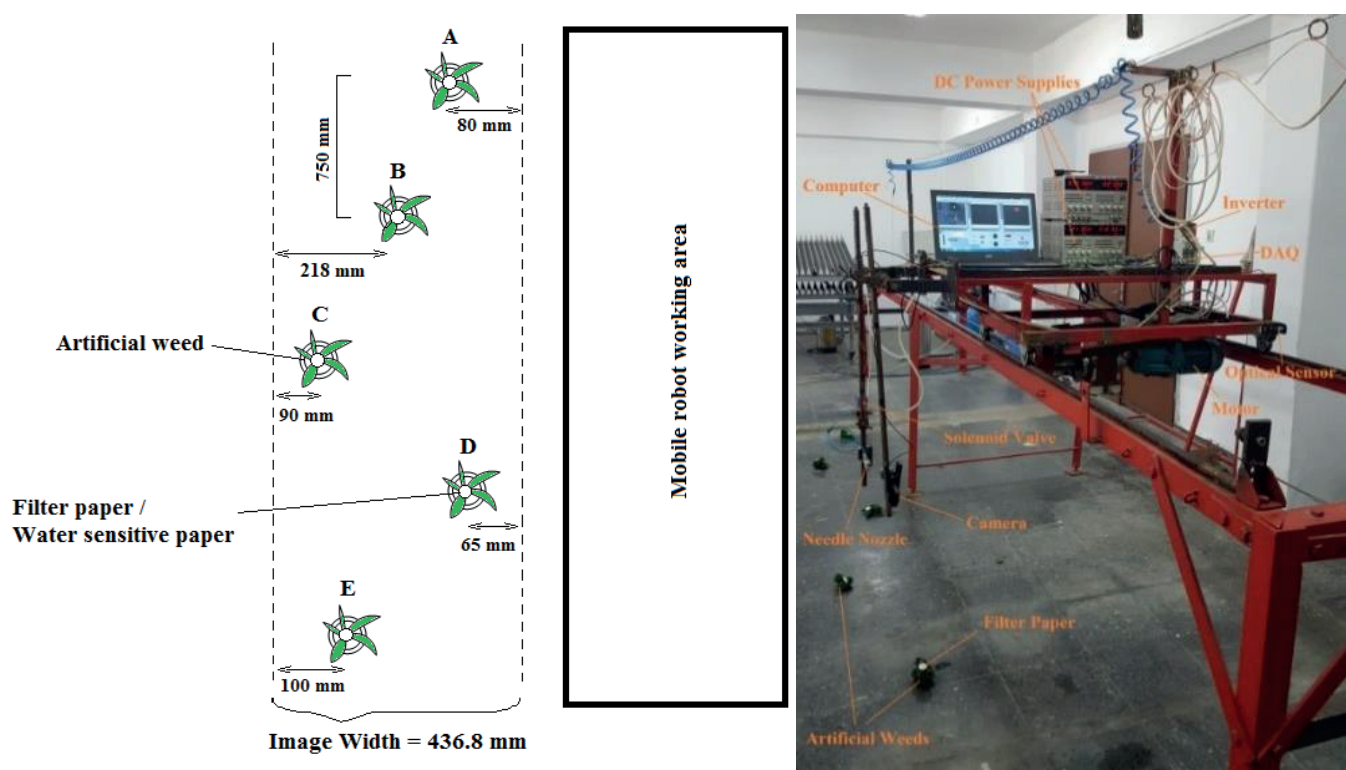

Figure 6. The layout of filter papers/water-sensitive papers attached to the artificial weeds and system design. 
A series was repeated three times at each travel speed. The fluorometric analysis method was used to analyse the amounts of tracer on the filter papers. A total of 75 ( $=5$ filter papers $\times 3$ replications $\times 5$ speeds) filter papers were collected during the experiments. BSF trace material, which has $460 \mathrm{~nm}$ excitation and $500 \mathrm{~nm}$ emission wavelengths, concentrated $0.4 \%$ in tap water was used to determine the deposition profile in the needle nozzle spray pattern with $200 \mathrm{kPa}$ spraying pressure. The sprayed filter paper targets were collected after the experiments and placed into glass jars to measure the amount of the deposits. Glass jars were shaken for 10 minutes after adding 20 $\mathrm{mL}$ of distilled water, and then, the filter papers were put into the spectrofluorophotometer for analysis. The fluorometric readings were converted to the real concentration values by using the following calibration equation (Equation 9):

$$
\begin{gathered}
y=2131.21 x+180.052 \\
r^{2}=0.99793
\end{gathered}
$$

where $y$ refers to the intensity, $x$ refers to the concentration values, and $r^{2}$ refers to the coefficient of determination.

The spraying efficiencies of the other locations ( $A, C, D$, and $E$ ) were compared with the middle location $(B)$ because the spraying needle was axially perpendicular to the artificial weed located in $B$, which is in the middle of the spraying width, as shown in Figure 6.

\section{Coverage rate determination}

In addition to the volumetric consumption and deposition tests, the coverage rate determination process of the micro-sprayer system was also evaluated.
For this purpose, three replicate trials were conducted during the experiments by using water-sensitive papers. The locations of the artificial weeds and water-sensitive papers were similar to the locations in the deposition experiments. Water-sensitive papers were also placed at the centres of the artificial weed targets for coverage rate determination. A total of 75 (= 5 water-sensitive papers $x$ 3 replications $\times 5$ speeds) water-sensitive papers were evaluated during the experiments. Water-sensitive papers were collected after the experiments and scanned with a scanner at a resolution of $300 \mathrm{dpi}$. The coverage rates of the water-sensitive papers were analysed and determined by the software developed with Vision Acquisition Software (Özlüoymak \& Bolat, 2020). Water-sensitive paper has a specially coated yellow side that turns blue when exposed to moisture. First, the developed software counted all coated pixels (blue pixels) that belonged to each of the water-sensitive papers. Next, yellow pixels were counted and added to the coated pixels to find the total pixels of the water-sensitive paper. The ratio of the liquid-contaminated area to the total area indicated the coverage rate. The thresholding method was also used in this procedure.

Comparison of the spraying efficiencies of the other locations ( $A, C, D$, and $E$ ) with the middle location (B) in accordance with the coverage rate was carried out to confirm the spraying efficiency results evaluated with the deposition data.

\section{Statistical analysis method}

Spray volume consumption, deposition amounts and coverage rates were evaluated by using the IBM SPSS statistical analysis 
program. Determining spraying duration, the effects of location and speed on the deposition analysis data and the coverage rate data were evaluated statistically.

\section{Results and Discussion}

\section{Object tracking and targeting performances}

The system automation, image acquisition-processing-targeting algorithms, steering of the servomotor and spraying process were characterized by LabVIEW and Vision Acquisition Software. Object tracking and targeting performances were tested at travel speeds of $0.42,0.54,0.66,0.78$ and 0.90 $\mathrm{kmh}-1$. During the experiments, it was observed that the mobile system identified and tracked all the artificial weed targets correctly and performed the steering action in accordance with the target coordinates. Furthermore, the spraying procedure was not applied when there was no artificial weed target. The object tracking and targeting performances of the mobile system were observed visually, and the spraying performancewas evaluatedaccording to the amount of deposition and coverage rate as determined by the appropriate tests. Experiments performed at speeds greater than $0.90 \mathrm{~km} \mathrm{~h}^{-1}$ were not performed since the mobile system did not have a braking system.

\section{Volumetric consumption tests}

Five randomly placed artificial weed samples were arranged in order at $750 \mathrm{~mm}$ intervals. Seven spraying durations were predetermined for the spraying procedure, tested on the artificial weeds, and replicated three times at $200 \mathrm{kPa}$ spraying pressure to find the minimum spraying duration. The minimum spraying duration of the system was determined based on the average consumption results.

The volumetric consumption data according to the spraying duration were subjected to one-way ANOVA tests performed with the SPSS program. I concluded that there was a significant difference between the groups according to the $p$-value (sig. $0.000<0.05$ ). According to the Duncan test used for post hoc analysis, the volumetric consumption data were collected in four groups, as shown in Table 1. 
Table 1

Duncan test analysis results

\begin{tabular}{|c|c|c|c|c|c|}
\hline \multicolumn{6}{|l|}{ Duncan $^{a}$} \\
\hline Spraying Duration & $\mathrm{N}$ & 1 & 2 & 3 & 4 \\
\hline $40 \mathrm{~ms}$ & 3 & 13,4000 & & & \\
\hline $50 \mathrm{~ms}$ & 3 & 13,4167 & & & \\
\hline $100 \mathrm{~ms}$ & 3 & 13,8867 & & & \\
\hline $200 \mathrm{~ms}$ & 3 & & 17,7333 & & \\
\hline $300 \mathrm{~ms}$ & 3 & & 19,2000 & & \\
\hline $400 \mathrm{~ms}$ & 3 & & & 22,6000 & \\
\hline $500 \mathrm{~ms}$ & 3 & & & & 25,4667 \\
\hline Sig. & & ,681 & ,203 & 1,000 & 1,000 \\
\hline
\end{tabular}

The means for the groups in homogeneous subsets are displayed.

a. Uses harmonic mean sample size $=3,000$.

There were significant differences between the 40, 50 and $100 \mathrm{~ms} ; 200$ and 300 $\mathrm{ms} ; 400 \mathrm{~ms}$; and $500 \mathrm{~ms}$ spraying durations according to the statistical test results. Since the 40 and $50 \mathrm{~ms}$ spraying durations were too close to each other in terms of consumption according to the statistical analysis results, a $50 \mathrm{~ms}$ spraying duration was selected in the experiments.

The average sprayvolume consumption test resulting in five artificial weed samples are also given in Figure 7. As shown in Figure 7 , the system managed to reach the minimum consumption at the $50 \mathrm{~ms}$ spraying duration because the electronically controlled solenoid valve and the relay on the relay card did not respond to the system with a response time less than $50 \mathrm{~ms}$. The consumption at spraying duration less than $50 \mathrm{~ms}$ remained almost the same. Therefore, the most advantageous spraying duration and average consumption for the five artificial weeds were also determined to be $50 \mathrm{~ms}$ and $13.42 \mathrm{~mL}$, respectively.

A servo-based target-oriented robotic weed control system was found to be more economical than the broadcast spraying method. The micro-dose spraying application with a 50 ms spraying duration saved $95 \%$ of the application volume on average for five artificial weeds compared to the broadcast spraying method. The volumetric consumption values for the micro-dose and broadcast spraying methods at different speeds are shown in Table 2. However, spray savings can vary by the number of weeds in the experimental area. 


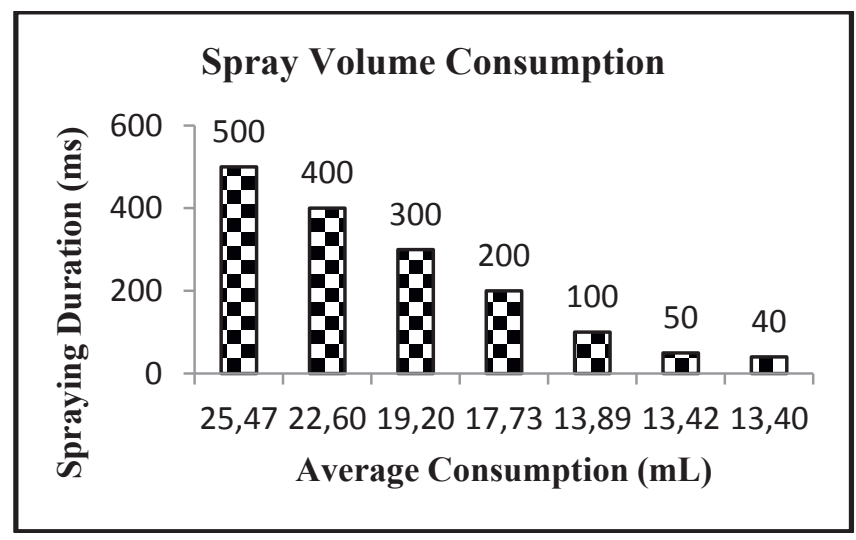

Figure 7. Spray volume consumption results of the system.

Table 2

Volumetric consumption values for micro-dose and broadcast spraying methods at different speeds

\begin{tabular}{cccc|} 
Speed $\left(\mathrm{km} \mathrm{h}^{-1}\right)$ & $\begin{array}{c}\text { Broadcast Spraying* } \\
\left(\mathrm{mL} / 4 \mathrm{~m}^{2}\right)\end{array}$ & $\begin{array}{c}\text { Micro-dose Spraying } \\
(\mathrm{mL} / 50 \mathrm{~ms})\end{array}$ & $\begin{array}{c}\text { Spray Saving } \\
(\% / 50 \mathrm{~ms})\end{array}$ \\
0.42 & 377 & 13.42 & 96.44 \\
0.54 & 313 & 13.42 & 95.71 \\
0.66 & 265 & 13.42 & 94.93 \\
0.78 & 236 & 13.42 & 94.31 \\
0.90 & 210 & 13.42 & 93.61 \\
Average & 280.20 & 13.42 & 95.00 \\
\hline
\end{tabular}

*Broadcast spraying was the reference for comparison

Deposition measurements on artificial weed samples

The travel speeds in the deposition measurement experiments were the same as the former test speeds. Three replicate trials were performed for five artificial weed targets placed at random locations along a row for each travel speed. Spectrofluorophotometric analysis results for the deposition measurements of the artificial weed samples placed in spraying locations $A, B, C, D$ and $E$ are presented in Figure 8. As expected, the amount of the deposits on artificial weeds decreased with increasing speed, although the spraying pressure of the system remained the same.
In all experiments, the highest deposition concentration was determined based on the artificial weed located in B. Therefore, the spraying efficiencies in the other locations (for A, C, D, and E spraying locations) of the micro-dose spraying system were compared with the $\mathrm{B}$ location. The results are given in Table 3.

For all travel speeds, while the nearest deposition concentration was determined for location $E$, the farthest deposition concentration was obtained for location $D$ compared with location B. Better spraying efficiency was determined when the artificial weed sample was located closer to the 
vertical point of the spraying needle nozzle (in the middle of the field of view). If the artificial weeds were located near the edges of the field of view, the spraying efficiency of the microdose mobile system decreased.

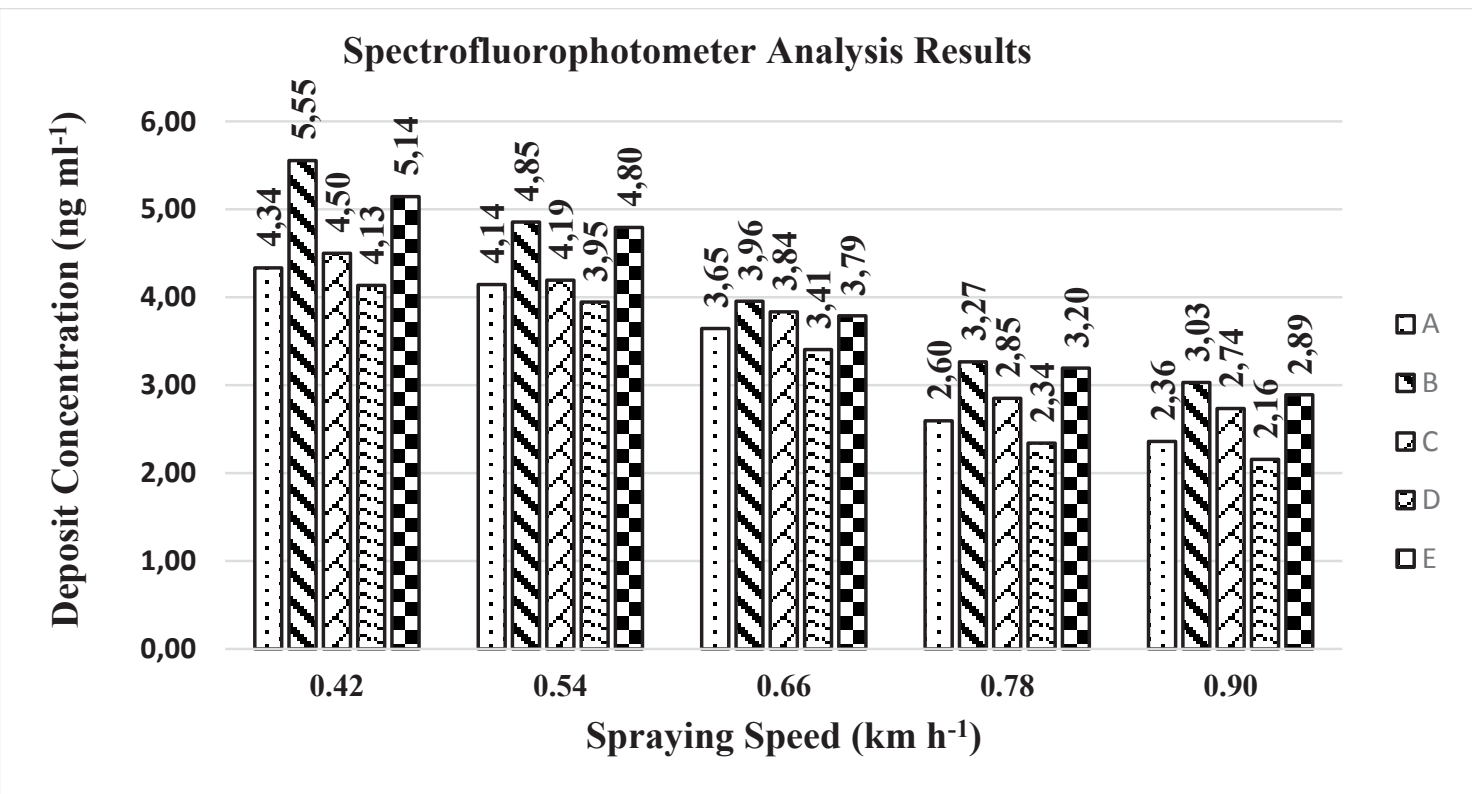

Figure 8. Average deposition of the mobile system at different spraying speeds for spraying locations $A, B, C, D$ and $E$.

Table 3

Spraying efficiency (\%) of the mobile micro-dose spraying system according to the deposition concentration

\begin{tabular}{|c|c|c|c|c|c|c|c|c|c|}
\hline \multirow{2}{*}{$\begin{array}{l}\text { Speed } \\
\left(\mathrm{km} \mathrm{h}^{-1}\right)\end{array}$} & \multicolumn{9}{|c|}{ Location } \\
\hline & $B^{*}$ & A & $\begin{array}{l}\text { Efficiency } \\
\text { (A to B)\% }\end{array}$ & C & $\begin{array}{l}\text { Efficiency } \\
\text { (C to B)\% }\end{array}$ & D & $\begin{array}{l}\text { Efficiency } \\
\text { (D to B)\% }\end{array}$ & E & $\begin{array}{c}\text { Efficiency } \\
\text { (E to B)\% }\end{array}$ \\
\hline 0.42 & 5.56 & 4.34 & 78.04 & 4.50 & 81.01 & 4.14 & 74.44 & 5.15 & 92.62 \\
\hline 0.54 & 4.86 & 4.15 & 85.38 & 4.20 & 86.41 & 3.95 & 81.26 & 4.80 & 98.76 \\
\hline 0.66 & 3.96 & 3.65 & 92.16 & 3.84 & 96.97 & 3.41 & 86.09 & 3.79 & 95.83 \\
\hline 0.78 & 3.27 & 2.60 & 79.48 & 2.85 & 87.29 & 2.34 & 71.67 & 3.20 & 97.86 \\
\hline 0.90 & 3.03 & 2.36 & 77.89 & 2.74 & 90.26 & 2.16 & 71.12 & 2.89 & 95.38 \\
\hline
\end{tabular}

*B location was the reference for comparison.

A two-way ANOVA test was performed with the data obtained, and the effects of the location and speed on the deposition analysis data were found to be significant (sig. $0.000<0.05)$. The deposition concentration data were collected in five groups based on the location and speed according to the Duncan test used in the post hoc analysis, as shown in Tables 4 and 5, respectively. 


\section{Table 4}

The effect of the location on the deposition analysis data

\begin{tabular}{|c|c|c|c|c|c|c|}
\hline \multicolumn{7}{|l|}{ Duncan a,b } \\
\hline \multirow{2}{*}{ Location } & \multirow{2}{*}{$N$} & \multicolumn{4}{|c|}{ Subset } & \multirow[b]{2}{*}{5} \\
\hline & & 1 & 2 & 3 & 4 & \\
\hline D & 15 & 3,1980 & & & & \\
\hline A & 15 & & 3,4180 & & & \\
\hline C & 15 & & & 3,6253 & & \\
\hline$E$ & 15 & & & & 3,9653 & \\
\hline B & 15 & & & & & 4,1340 \\
\hline Sig. & & 1,000 & 1,000 & 1,000 & 1,000 & 1,000 \\
\hline
\end{tabular}

The means for the groups in homogeneous subsets are displayed.

Based on observed means. The error term is mean square (error) $=.001$.

a. Uses harmonic mean sample size $=15,000$. b. Alpha $=.05$.

\section{Table 5}

The effect of the speed on the deposition analysis data

\begin{tabular}{|c|c|c|c|c|c|c|}
\hline \multicolumn{7}{|l|}{ Duncana,b } \\
\hline \multirow{2}{*}{$\begin{array}{c}\text { Speed } \\
\left(\mathrm{km} \mathrm{h}^{-1}\right)\end{array}$} & \multirow{2}{*}{$\mathrm{N}$} & \multicolumn{4}{|c|}{ Subset } & \multirow[b]{2}{*}{5} \\
\hline & & 1 & 2 & 3 & 4 & \\
\hline 0.90 & 15 & 2,6367 & & & & \\
\hline 0.78 & 15 & & 2,8513 & & & \\
\hline 0.66 & 15 & & & 3,7280 & & \\
\hline 0.54 & 15 & & & & 4,3887 & \\
\hline 0.42 & 15 & & & & & 4,7360 \\
\hline Sig. & & 1,000 & 1,000 & 1,000 & 1,000 & 1,000 \\
\hline
\end{tabular}

The means for the groups in homogeneous subsets are displayed.

Based on observed means. The error term is mean square (error) $=.001$.

a. Uses harmonic mean sample size $=15,000$. b. Alpha $=.05$.

\section{Coverage rate determination}

Novel image-processing software developed with NI Vision Acquisition Software was used to determine the spray coverage rates as measured using water-sensitive paper. The steps of the image processing used to find the coverage rates with water-sensitive papers are demonstrated in Figure 9. The samples were placed as shown in Figure 6, and the spraying procedure was performed for all five artificial weed samples, namely, $A, B, C, D$, and $E$, which were named according to their location. 


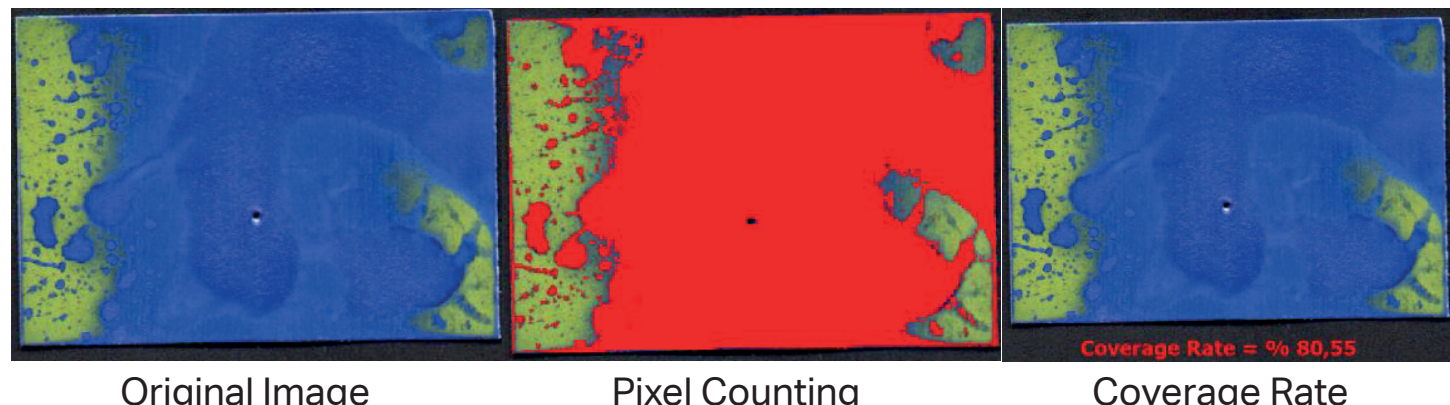

Figure 9. The image-processing steps of a water-sensitive paper sample.

The coverage rate results for the steerable spraying needle nozzle at travel speeds of $0.42,0.54,0.66,0.78$ and $0.90 \mathrm{~km}$ $\mathrm{h}^{-1}$ are given in Figure 10. The results showed that the coverage rate did not dramatically decrease even when the system reached higher speeds. The results also demonstrated that the system did not conspicuously lose its sharp-shooting ability or hitting efficiency with increasing speed; these results are shown in Figure 10.
According to the coverage rate results, the highest coverage rate was also determined for all travelling speeds on the artificial weed located in B. Thus, the spraying efficiency of location $\mathrm{B}$ was compared with the spraying efficiencies of the other locations (for spraying locations $A, C, D$, and E). The spraying efficiency of the mobile micro-dose spraying system is given in Table 6.

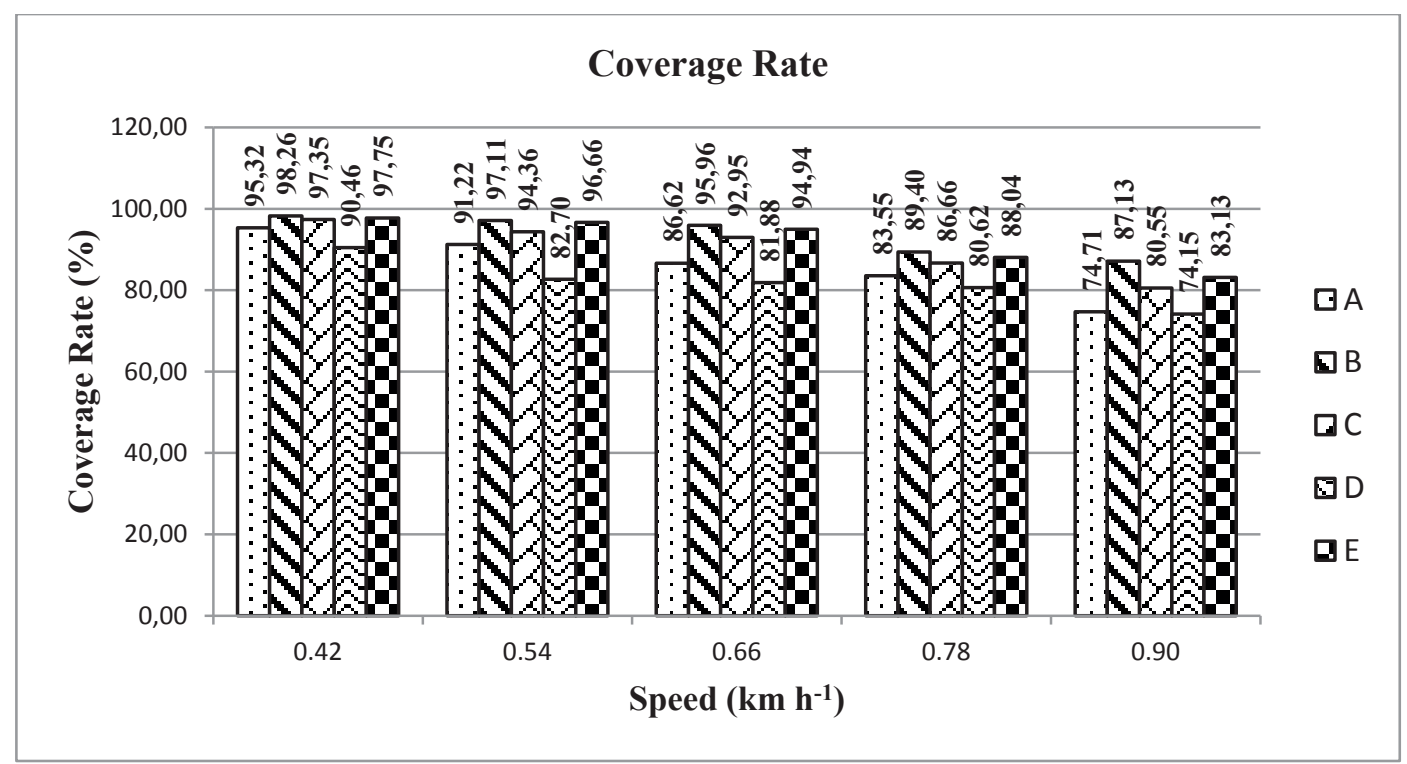

Figure 10. Coverage rate results of the steerable spraying needle nozzle at different spraying speeds for spraying locations $A, B, C, D$ and $E$.. 
Table 6

Spraying efficiency (\%) of the mobile micro-dose spraying system according to the coverage rate

\begin{tabular}{|c|c|c|c|c|c|c|c|c|c|}
\hline \multirow{2}{*}{$\begin{array}{c}\text { Speed } \\
\left(\mathrm{km} \mathrm{h}^{-1}\right)\end{array}$} & \multicolumn{9}{|c|}{ Location } \\
\hline & $\mathrm{B}^{*}$ & A & $\begin{array}{l}\text { Efficiency } \\
\text { (A to B)\% }\end{array}$ & C & $\begin{array}{l}\text { Efficiency } \\
\text { (C to B)\% }\end{array}$ & D & $\begin{array}{l}\text { Efficiency } \\
\text { (D to B)\% }\end{array}$ & E & $\begin{array}{l}\text { Efficiency } \\
\text { (E to B)\% }\end{array}$ \\
\hline 0.42 & 98.26 & 95.32 & 97.01 & 97.35 & 99.08 & 90.46 & 92.06 & 97.75 & 99.48 \\
\hline 0.54 & 97.11 & 91.22 & 93.93 & 94.36 & 97.17 & 82.70 & 85.17 & 96.66 & 99.54 \\
\hline 0.66 & 95.96 & 86.62 & 90.26 & 92.95 & 96.86 & 81.88 & 85.33 & 94.94 & 98.94 \\
\hline 0.78 & 89.40 & 83.55 & 93.46 & 86.66 & 96.94 & 80.62 & 90.17 & 88.04 & 98.48 \\
\hline 0.90 & 87.13 & 74.71 & 85.74 & 80.55 & 92.45 & 74.15 & 85.10 & 83.13 & 95.41 \\
\hline
\end{tabular}

*Location $B$ was the reference for comparison.

Similar to the results in the amount of deposition, while the coverage rate nearest to location $B$ was determined for location $E$, the farthest coverage rate to location $B$ was obtained for location D for all travel speeds in the study. As expected, better spraying efficiency was determined when the artificial weed was located closer to the vertical point of the spraying needle nozzle (in the middle of the field of view). The spraying efficiency of the micro-dose mobile system also decreased for the artificial weed samples closer to the edges, similar to the deposition analysis results.

Two-way ANOVA was applied to the coverage data obtained, and the effects of location and speed on the coverage rate were found to be significant (sig. $0.000<0.05$ ). The coverage rate data were collected in five groups based on the location and speed according to the Duncan test in the post hoc analysis, as shown in Tables 7 and 8, respectively.

\section{Table 7}

\section{The effect of location on the coverage rate data}

\begin{tabular}{|c|c|c|c|c|c|c|}
\hline \multirow[t]{2}{*}{ Duncan $^{a, b}$} & & \multicolumn{4}{|c|}{ Subset } & \multirow[b]{2}{*}{5} \\
\hline & IN & 1 & 2 & 3 & 4 & \\
\hline$D$ & 15 & 81,9613 & & & & \\
\hline A & 15 & & 86,2840 & & & \\
\hline $\mathrm{C}$ & 15 & & & 90,3773 & & \\
\hline$E$ & 15 & & & & 92,1047 & \\
\hline B & 15 & & & & & 93,5727 \\
\hline Sig. & & 1,000 & 1,000 & 1,000 & 1,000 & 1,000 \\
\hline
\end{tabular}

The means for groups in the homogeneous subsets are displayed.

Based on the observed means. The error term is mean square(error) $=.001$.

a. Uses harmonic mean sample size $=15,000$. b. Alpha $=.05$. 


\section{Table 8}

\section{The effect of speed on the coverage rate data}

\begin{tabular}{|c|c|c|c|c|c|c|}
\hline \multicolumn{7}{|l|}{ Duncan $^{\mathrm{a}, \mathrm{b}}$} \\
\hline \multirow{2}{*}{$\begin{array}{c}\text { Speed } \\
\left(\mathrm{km} \mathrm{h}^{-1}\right)\end{array}$} & \multirow{2}{*}{$\mathrm{N}$} & \multicolumn{4}{|c|}{ Subset } & \multirow[b]{2}{*}{5} \\
\hline & & 1 & 2 & 3 & 4 & \\
\hline 0.90 & 15 & 79,9347 & & & & \\
\hline 0.78 & 15 & & 85,6560 & & & \\
\hline 0.66 & 15 & & & 90,4727 & & \\
\hline 0.54 & 15 & & & & 92,4100 & \\
\hline 0.42 & 15 & & & & & 95,8267 \\
\hline Sig. & & 1,000 & 1,000 & 1,000 & 1,000 & 1,000 \\
\hline
\end{tabular}

The means for groups in the homogeneous subsets are displayed. Based on the observed means. The error term is mean square(error) $=.001$. a. Uses harmonic mean sample size $=15,000$. b. Alpha $=.05$.

\section{Conclusion}

A servo-based target-oriented robotic weed control system equipped with a camera was designed, developed, and tested for controlling a micro-dose spraying system on artificial weed samples. The experiments were performed in indoor environments, and the mobile system successfully travelled back and forth, processed images, and sprayed at high precision. The colour segmentation algorithm was used to discriminate floor and vegetation by using the greenness method. The real-time system was automatically controlled by using LabVIEW and image-processing software developed for experimental purposes. The prototype system effectively detected, tracked, targeted and sprayed artificial weeds at speeds of $0.42,0.54,0.66,0.78$ and $0.90 \mathrm{~km}$ $\mathrm{h}^{-1}$ and under a spraying pressure of $200 \mathrm{kPa}$.

The micro-dose spraying system was found to be more economical than the broadcast spraying method. The micro-dose spraying application with a $50 \mathrm{~ms}$ spraying duration saved $95 \%$ of the application volume, on average, for five artificial weeds.

When the spraying efficiency of the developed micro-dose system was evaluated according to the deposition and coverage rate data, there was a difference between the artificial weed samples in the middle location or at the edge of the field of view. Higher spraying efficiency was determined in the middle locations than in the edge locations at the same spraying pressure.

From the perspective of the types of herbicides to be applied to a plant, systemic herbicides are extensively translocated in the vascular system of a plant from aspect of absorption (leaf or root) to the sites of action, while contact herbicides kill only the portion of green tissue contacted. Hence, while the entire plant must be sprayed with contact herbicides, a drop of systemic herbicide placed on a leaf tip can be enough to eliminate the weed. From this standpoint, the servo-based real-time target-oriented precision weed control system developed in this study is suitable for use with 
systemic herbicides under field conditions. As new technologies and techniques for spraying systems continue to emerge, studies on weed segmentation and widespread use of smart sprayers will improve spraying efficiencies and reduce the negative impact of agrochemical inputs on the environment. As discussed earlier, this study was developed for interrow applications. The lack of stereo imaging technology in weed segmentation is the main limitation of robotic weed control systems. Future research can further propose a precision weed control system for intra-row weed-sensing applications by using the stereo imaging techniques.

\section{Acknowledgments}

This work was supported by the Çukurova University Scientific Research Projects Department, Project Number: FBA2016-6793.

\section{References}

Berenstein, R., \& Edan, Y. (2017). Humanrobot collaborative site-specific sprayer. Journal of Field Robotics, 34(8), 15191530. doi: 10.1002/rob.21730

Blasco, J., Aleixos, N., Roger, J. M., Rabatel, G., \& Moltó, E. (2002). Robotic weed control using machine vision. Biosystems Engineering, 83(2), 149-157. doi: 10.1006/ bioe.2002.0109

Gonzalez, R. C., Woods, R. E., \& Masters, B. R. (2008). Digital image processing (vol. 14). Upper Saddle River, NJ: Prentice Hall.

Gonzalez-de-Soto, M., Emmi, L., Perez-Ruiz, M., Aguera, J., \& Gonzalez-de-Santos, P. (2016). Autonomous systems for precise spraying - Evaluation of a robotised patch sprayer. Biosystems Engineering, 146(2016), 165-182. doi: 10.1016/j. biosystemseng.2015.12.018

Jafari, A., Jahromi, H. E., Mohtasebi, S., \& Omid, M. (2006a). Color segmentation scheme for classifying weeds from sugar beet using machine vision. International Journal of Information Science and Management (IJISM), 4(1), 1-12.

Jafari, A., Mohtasebi, S., Jahromi, H., \& Omid, M. (2006b). Weed detection in sugar beet fields using machine vision. International Journal of Agriculture and Biology, 8(5), 602-605.

Lamm, R. D., Slaughter, D. C., \& Giles, D. K. (2002). Precision weed control system for cotton. Transactions of the ASAE, 45(1), 231-238. doi: $10.13031 / 2013.7861$

Lee, W. S., Slaughter, D. C., \& Giles, D. K. (1999). Robotic weed control system for tomatoes. Precision Agriculture, 1(1), 95113. doi: 10.1023/a:1009977903204

Loghavi, M., \& Mackvandi, B. B. (2008). Development of a target oriented weed control system. Computers and Electronics in Agriculture, 63(2), 112-118. doi: 10.1016/j.compag.2008.01.020

Loni, R., Loghavi, M., \& Jafari, A. (2014). Design, development and evaluation of targeted discrete-flame weeding for inter-row weed control using machine vision. American Journal of Agricultural Science and Technology, 2(1), 17-30. doi: 10.7726/ ajast.2014.1003

Meyer, G. E., \&, Camargo, J. Neto. (2008). Verification of color vegetation indices for automated crop imaging applications. Computers and Electronics in Agriculture, 
63(2), 282-293. doi: 10.1016/j. compag. 2008.03.009

Midtiby, H. S., Mathiassen, S. K., Andersson, K. J., \& Jørgensen, R. N. (2011). Performance evaluation of a crop/weed discriminating microsprayer. Computers and Electronics in Agriculture, 77(1), 35-40. doi: 10.1016/j. compag.2011.03.006

Nieuwenhuizen, A. T., Hofstee, J. W., \& van Henten, E. J. (2010). Performance evaluation of an automated detection and control system for volunteer potatoes in sugar beet fields. Biosystems Engineering, 107(1), 46-53. doi: 10.1016/j. biosystemseng.2010.06.011

Özlüoymak, Ö. B., \& Bolat, A. (2020). Development and assessment of a novel imaging software for optimizing the spray parameters on water-sensitive papers. Computers and Electronics in Agriculture, 168(2020), 105104. doi: 10.1016/j. compag.2019.105104

Sabanci, K., \& Aydin, C. (2017). Smart robotic weed control system for sugar beet. Journal of Agricultural Science and Technology, 19(1), 73-83.

Shirzadifar, A., Loghavi, M., \& Raoufat, M. (2013). Development and evaluation of a real time site-specific inter-row weed management system. Iran Agricultural Research, 32(2), 39-54. doi: 10.22099/IAR. 2015.2004

Song, Y., Sun, H., Li, M., \& Zhang, Q. (2015). Technology application of smart spray in agriculture: a review. Intelligent Automation \& Soft Computing, 21(3), 319-333. doi: 10.1080/10798587.2015.1015781

Tangwongkit, R., Salokhe, V., \& Jayasuriya, H. W. (2006). Development of a realtime, variable rate herbicide applicator using machine vision for between-row weeding of sugarcane fields. Agricultural Engineering International: CIGR Journal, Manuscript PM 06 009, 8, 1-12.

Tellaeche, A., Burgos-Artizzu, X. P., Pajares, G., \& Ribeiro, A. (2008). A vision-based method for weeds identification through the Bayesian decision theory. Pattern Recognition, 41(2), 521-530. doi: 10.1016/ j.patcog.2007.07.007

Tian, L. (2002). Development of a sensor-based precision herbicide application system. Computers and Electronics in Agriculture, 36(2-3), 133-149. doi: 10.1016/s01681699(02)00097-2

Timmermann, C., Gerhards, R., \& Kühbauch, W. (2003). The economic impact of site-specific weed control. Precision Agriculture, 4(3), 249-260. doi: 10.1023/ a:1024988022674

Underwood, J. P., Calleija, M., Taylor, Z., Hung, C., Nieto, J., Fitch, R., \& Sukkarieh, S. (2015). Real-time target detection and steerable spray for vegetable crops. Sydney: Sydney Univ. Retrieved from http://confluence.acfr.usyd.edu.au/ download/attachments/14452007/2015Underwood-ICRAAgWs-Spray.pdf?versio $\mathrm{n}=1$ \& modificationDate $=1465979705000$ \&api=v2

Wan Ishak, W. I., \& Rahman, K. A. (2010). Software development for real-time weed colour analysis. Pertanika Journal of Science \& Technology, 18(2), 243-253.

Xiong, Y., Ge, Y., Liang, Y., \& Blackmore, S. (2017). Development of a prototype robot and fast path-planning algorithm for static laser weeding. Computers and Electronics in Agriculture, 142(2017), 494-503. doi: 10.1016/j.compag.2017.11.023 
Yang, C.-C., Prasher, S. O., Landry, J.-A., \& Kok, R. (2002). A vegetation localization algorithm for precision farming. Biosystems Engineering, 81(2), 137-146. doi: 10.1006/ bioe.2002.0006

Yang, C.-C., Prasher, S. O., Landry, J.-A., \& Ramaswamy, H. S. (2003). Development of an image processing system and a fuzzy algorithm for site-specific herbicide applications. Precision Agriculture, 4(1), 5-18. doi: 10.1023/a:1021847103560

Young, S. L., \& Giles, D. K. (2013). Targeted and microdose chemical applications. In S. L. Young, \& F. J. Pierce (Eds.), Automation: the future of weed control in cropping systems (pp. 139-147). Netherlands: Springer.
Zhang, Y., Staab, E. S., Slaughter, D. C., Giles, D. K., \& Downey, D. (2012). Automated weed control in organic row crops using hyperspectral species identification and thermal micro-dosing. Crop Protection, 41(2012), 96-105. doi: 10.1016/j.cropro. 2012.05.007

Zhao, D., Zhao, Y., Wang, X., \& Zhang, B. (2016). Theoretical design and first test in laboratory of a composite visual servobased target spray robotic system. Journal of Robotics, 2016(3), 1-11. doi: 10. $1155 / 2016 / 1801434$ 